\title{
Development of Community-Based Tourism Monbang Village - Alor, Indonesia
}

\author{
Elim Lau, Melky Kabu, Samson Lobang \\ \{elimralau@gmail.com,melki_kabu@yahoo.co.id, salilobang@gmail.com\} \\ Politeknik Negeri Kupang
}

\begin{abstract}
Monbang Village is located in Alor Regency which has a unique traditional clothing culture and is made by tree bark and the local community usually calls the $\mathrm{Ka}$ Tree. In addition, the village also has traditional dances such as lego-lego and cakalele and they have other activities which is they make fires from bamboo. Through tourism cases studes, this paper critically analyzes how well community-based tourism is generally accepted with reality in the field. It focuses on how local community handle their roles as ambassador to maintain their unique daily lives. Community members are often the only "locals" who are visited by many tourists. This study tries to make the project development community method by the community and the need for an effective exit strategy with SWOT analysis.
\end{abstract}

Keywords: community-based tourism: cultural tourism; local community

\section{Introduction}

Tourism is one of the most important economic activities in the world today, because it directly generates services, products, foreign currency, employment and investment. In Indonesia, tourism has become a flourishing service industry, it has a far-reaching economic and social impact on national development. According to [1] To make the community development through tourism industry, it is necessary to put in place a system of training and professional education with necessary infrastructural support capable of generating manpower sufficient to meet the needs of the tourism and hospitality industry, both quantitatively and qualitatively.

A community-based to approach to tourism development has long been advocated by everyone who have concern in tourism industry [2]. They always speak about sustainability of tourism and of great importance to planners, managers and operators. It is believed that, for sustainable tourism to occur, local residents should have inputs into the decisions that affect them and their families and communities. Community participations in tourism initiatives should always be encouraged because it makes the planning process more effective, equitable and legitimate [3].

Alor Regency is a land of splendid destination with rich cultural heritage, historical heritage, flora and fauna, spectacular beaches and mountain and wildlife. Tourism has various dimensions in various aspects like economic, social, demographic, technological, geographical, cultural, natural and so many fields. The attractions of tourist have been growing up on the above stated types of dimensions. Tourism now has laid down emphasis on the rural areas. In the context of 
community-based tourism, it is necessary to take vital steps which are constructive and positive. Tourism is also an employment oriented sector.

\section{Objectives this study}

The literature review identified a number of gaps and weakness in the existing literature on tourism development in destination regions [4]. The overall aim of this study was to build upon these resources by analyzing the role of tourism and its impact on community-based tourism development in the study region.

The present paper is structured to elucidate with the following main objectives:

a. To find out the strength of attraction in Monbang Village

b. To impart knowledge and develop skills oriented to the nature and needs of the communitybased tourism for present and future needs.

\section{Community based tourism}

In the context of sustainable tourism development, the importance of CBT has clearly been recognized over the past two decades. Nobody will dispute the fact that destination communities must benefit if tourism is to be viable and sustainable in the long term. CBT aims to create. CBT aims to create a more sustainable tourism industry, focusing on the receiving communities in terms of planning and maintaining tourism development [2].

The anticipated benefits of CBT are three, Rozemeijer, 2001 (In Salazar, 2012) [2]

a. CBT generates income and employment and, such as, contributes to rural development - a benefit that especially applies in remote areas.

b. The benefits derived from the use of natural resources for tourism will prompt the community to use these valuable resources in a sustainable way; and

c. CBT adds value to the national tourism product through diversification of tourism, increasing volume and economies of scale.

These tourism programs may also enhance the opportunity for spontaneous, rather than contrived, encounters between destination communities and tourists. For these reasons, intergovernmental agencies like ONWTO and UNESCO have singled out cultural and heritage tourism as the most suitable form of community-based development for developing countries. For many people, (sustainable) cultural tourism development is actually synonymous with CBT involving local people. Lamers, 2001 (in Salazar, 2012). While the notion of CBT stresses that many of these projects and products are indeed focused on a local community (and its natural and cultural heritage), in practice, they are seldom controlled and managed by that community - "community-centered tourism" would actually be a more accurate term.

\section{Research Method}

This is a qualitative study, guided by the grounded theory approach Bryant \& Charmaz, 2007 (in Salazar, 2012) [2] whereby descriptive research leads to the development of more meaningful theory and measures. It critically analyzes how the generally accepted CBT principles, as outline above, resonate with the reality on the ground with interview method. Indepth interviews along with semi-structured interviews with five people (Village chief, head of tourism office, Monbang public figure, local people) involved in development of community based tourism. Almost all the respondent agreed to answer some questions in interview guide 
that collected basic demographic information and data on their education, and all about attraction in Monbang Village. Retrieval system of data sources / subjects of this study using purpose sampling techniques namely retrieval of data sources / subjects based on research choices about what aspects and who is the focus at certain situations and at that time continuously throughout the study. [5]

\section{SWOT Analysis}

According to David (2006) SWOT is [6]:

Strength : Strength are resources, skills, or other advantages associated with company competencies and market needs that can be questioned by companies that are expected to be done. Strength is a special competition that gives companies a competitive advantage in the market.

Weakness : Weakness are limitations or deficiencies in resources, skills and capabilities that effectively impede company performance. These limitations in the form of facilities, financial, resources, management capabilities and marketing skills can be source of community weakness.

Opportunities : Opportunities are important favorable situation in the community. An important is one source of opportunity, such as technological change and increased relations between companies and buyer or suppliers is a picture or opportunities for the communities.

Threats : Threats are important situations that are not profitable in the community. Threats are also major disturbance in the current position or desired the community.

\section{SWOT Matrix}

Table 1. SWOT matrix

\begin{tabular}{|c|c|c|}
\hline Internal factors & $\begin{array}{l}\text { Strengths }(\mathrm{S}) \\
\text { Internal Strengths }\end{array}$ & $\begin{array}{l}\text { Weakness }(\mathrm{W}) \\
\text { Internal weaknesses }\end{array}$ \\
\hline External factors & & \\
\hline \multirow{2}{*}{$\begin{array}{l}\text { Opportunities }(\mathrm{O}) \\
\text { External Opportunities }\end{array}$} & SO strategy & WO strategy \\
\hline & $\begin{array}{l}\text { Taking advantage of } \\
\text { strengths in favor of } \\
\text { opportunities. }\end{array}$ & $\begin{array}{l}\text { Overcoming a weakness by } \\
\text { taking advantage of } \\
\text { opportunity. }\end{array}$ \\
\hline \multirow{2}{*}{$\begin{array}{l}\text { Threats }(\mathrm{T}) \\
\text { External Threats }\end{array}$} & ST strategy & WT strategy \\
\hline & $\begin{array}{l}\text { Taking advantage of } \\
\text { strength to prevent threat }\end{array}$ & $\begin{array}{l}\text { Minimization of weakness } \\
\text { and avoidance of threat }\end{array}$ \\
\hline
\end{tabular}




\section{Results}

a. Strength :

1. The uniqueness of culture and customs.

The traditional village of Monbang is one of the new and unique tourist destinations for tourist. This is because the uniqueness and authenticity of the village is very different from others traditional villages in this case traditional clothing that made from bark of Ka Tree.

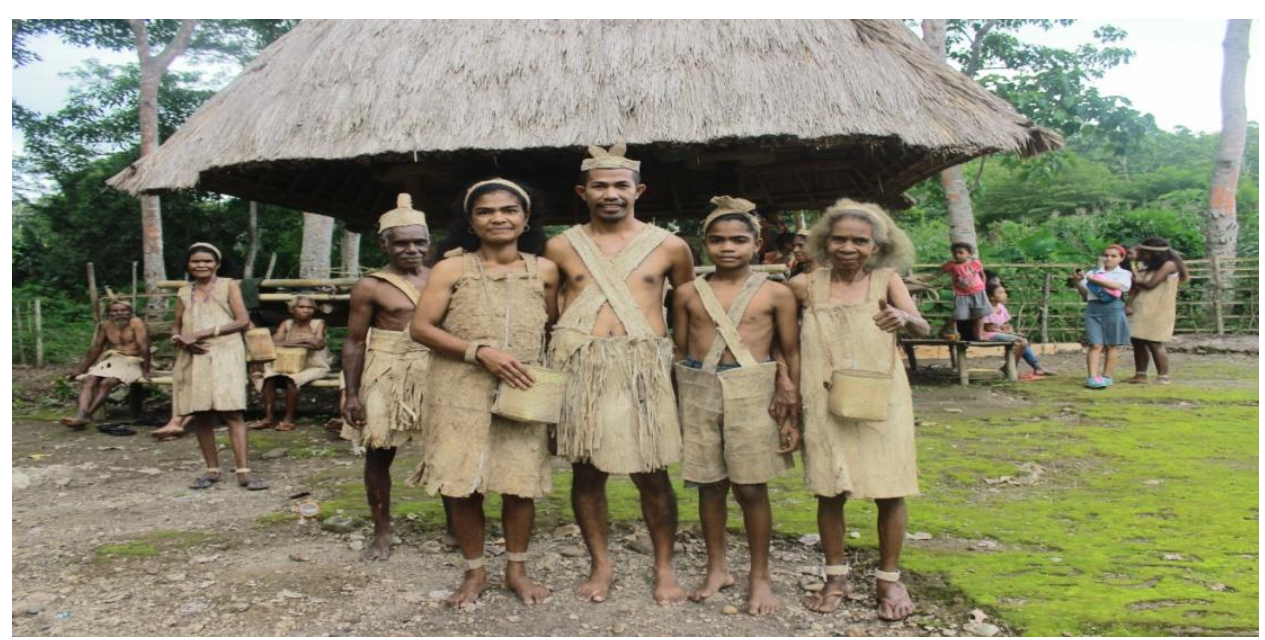

Picture 1. Local people with traditional clothing from bark.

2. The beauty of nature panorama.

The traditional of village Monbang offers a panoramic view of green beauty with the expanse of candlenut trees and Ka Trees (local language) and the original natural and cool environment so it is more interesting to visit.

3. Friendliness of the local people.

The hospitality of the community and the atmosphere of life in the village is one of honesty of the community that express feelings through real actions when they meet the tourist and this is an interesting attraction and able to make tourist comfortable with a good impression.

b. Weakness.

1. Human resources

Local people do not really understand about community-based tourism as well as obstacles in providing information for foreign tourists, so training or guidance is needed to the people in Monbang Village

2. Facilities

The existence of facilities certainly supports all tourism activities in Monbang village. But the lack of supporting facilities such as parking areas, trash bins, toilets, and information boards will affect the environment around attraction and the instability of tourist activities. 


\section{Promotion}

Promotional activities carried out to introducing Monbang Village have not been maximized. This is seen by the lack of local and foreign tourist arrival.

c. Opportunities

1. The tourism sector is growing

This affects the interest of tourists visiting to come to the Monbang village.

2. Can create business opportunities for local communities

The results of interviews with local people that the existences of this tourist's attraction is able to have a positive impact on the economic community. Where they provide several types of tour package and also local guide and home stay services.

d. Threats

1. External cultural influences

This is very important task for the local community to maintaining the authenticity and preservation of the culture that has been owned for several generations and must also be passed on young generation.

2. Competitor

Alor regency is known for having quite unique and many cultural tourism potentials.

So it is not surprising that there are many traditional village visits by tourist. Beside Monbang Village, there are also Takpala traditional village which are frequently visited by tourists.

\section{SWOT Strategy}

a. SO Strategy

1. Strengthen cultural identity by introducing to foreign countries

2. Increase the availability of attractive tourism products by selling local snacks, handy craft, souvenir, and others.

3. Create tour packages that are able to attract domestic and foreign tourists.

4. Increase participation and community participation in building culture and tourism.

\section{b. WO Strategy}

1. Increasing human resources by conducting socialization and education related to tourism and more training.

2. Massive promotion in various fields by distributing pamphlets, brochure, and social media

c. WT Strategy

1. Increase human resource by utilizing and stabilizing each local product to be able to compete with other tourist destinations.

2. Work on and add facilities by cooperating through the local government.

3. Continue to increase promotional efforts through social media by affirming that there is a local culture that is still maintained until now 


\section{d. $\quad$ ST Strategy}

1. The unique culture and customs will be able to compete with others cultural attractions.

2. Making the uniqueness of the natural panorama more prominent and interesting so that tourist will be interested and keep visiting.

\section{Conclusion}

Tourism is a human experience, a social experience, a geographical phenomenon, a resource value, and business industry. Tourism is widely recognized as the world's largest industry which plays an important role for human resource development. Yet tourism is also highly dynamic and is strongly influenced by economic, social, environmental, and technological change. The success of a community depends on its ability to affect continuous improvement and provide quality products and services to its customer. This will require every personnel in the community to process the requisite knowledge, skill and attitude.

Tourism in Monbang traditional village have seen no lapse in the previous decades. They have an unique attraction in their village is clothes from bark of Ka tree, lego-lego dancing, another culture ritualism. Thus, local people has a major role to play for the development of yhis sector.

Head of local people should be taken on a priority basis and adequate planning measures should be done accordingly because efficient human resources can increase tourists satisfaction, and create a competitive edge in this globalize world.

The tourism industry has achieved new dimension with visitors coming from near and far, to enrich and experience to wear a clothes from bark, taste the flavor of Monbang coffee, and feels the nature beauty. Most of local people are not engaged in tourism industry directly. Therefore they need training to increase their awareness about the importance of tourism and their income increases during the tourists season. Tourism is not only an economic activity of importance to Monbang's development, but also an important medium of cultural exchange among various nations of the world.

Over the last view decades, Monbang has not has the right development support. Even so, the people who are charming, sincere, and friendly in this place continue to try hard and succeed in maintaining the pride of clothing from bark as one of the best places for tourism even today.

\section{References}

[1] Butia, S.: The role of tourism for human resources development in Darjeeling district (2014)

[2] Salazar, N,B.: Community-based cultural tourism : issues, threats and opportunities (2012)

[3] Mayara Geofrey, Eleri Jones : Community-based tourism (2009)

[4] Rajesh: Impact of tourist perceptions, destination image and tourist satisfaction on destination loyalty (2013)

[5] Iorio M, Andrea Corsale: Community-based tourism and networking (2014)

[6] David, Fred R.: Strategic Management $10^{\text {th }}$ edition (2006) 